\title{
An in-silico analysis of information sharing systems for adaptable resources management: a case study of oyster farmers
}

\author{
Nicolas Paget ${ }^{1,2}$, Bruno Bonté ${ }^{1}$, Olivier Barreteau ${ }^{1}$, Gabriella Pigozzi $^{2}$ and Pierre Maurel ${ }^{3}$ \\ ${ }^{1}$ UMR G-EAU, Irstea, Montpellier Univ., Montpellier, France \\ ${ }^{2}$ Université Paris-Dauphine, PSL Research University, CNRS, LAMSADE, Paris, France \\ ${ }^{3}$ UMR TETIS, Irstea, Montpellier Univ., Montpellier, France
}

\begin{abstract}
Information sharing systems are often viewed as a potential way of increasing scrutiny by actors of their interactions with natural resources. Scrutiny is then seen as encouraging sustainable and adaptable management of the resource. We tackle this claim by using an agent-based model to focus on the specific issue of oyster farmers dealing with the deadly OsHV-1 virus by sharing information about their own experience (practices and outcomes) via their social network and/or an information sharing system. We followed closely what access to such information sharing means for the environment (production), agents (beliefs) and interactions between the environment and agents (practices). In the model, introducing information sharing leads to a decrease in mortality rates and a convergence in agents' beliefs. Agents stop changing their practices earlier when they share information, but heterogeneity in agent decision-making models leads to wider exploration of possible strategies and increased production. Agent-based modelling proved a suitable method for studying the impacts of information sharing.
\end{abstract}

\section{Keywords}

Information sharing, Oyster farming, Agent-based model, CORMAS

\section{Code availability}

The VirusNoysters model was developed using Cormas v.2014.5.14 (Bousquet et al., 1998; Le Page et al., 2012) and analysed using R v3.2.1. (R Core, 2015). The model code and dependent data, including scripts to analyse the outputs, are publicly available at: https://doi.org/10.5281/zenodo.2546505.

\section{Introduction}

In the age of information, local environmental information sharing systems, such as information systems or documents, are thought to be a possible way for actors in a social-ecological system to increase their scrutiny of their environment and the resources that they use and share (Young et al., 2006). In such systems, actors are fundamentally connected to and by a collective resource, such as fish stock, an irrigation network or a forest (Berkes and Folke, 1998; McGinnis and Ostrom, 2014; Ostrom, 2007). The practices of some actors impact the

\footnotetext{
Correspondence:

Contact N. Paget at nicolas.paget@cirad.fr

Cite this article as:

Paget, N., A., Bonté, B., Barreteau, O., Pigozzi, G. \& Maurel, P.

An in-silico analysis of information sharing systems for adaptable resources management: a case study of oyster farmers

Socio-Environmental Systems Modelling, vol. 1, 16166, 2019, doi:10.18174/sesmo.2019a16166

This work is licensed under a Creative Commons Attribution-NonCommercial 4.0 International License.

\section{Socio-Environmental Systems Modelling}

An Open-Access Scholarly Journal 
practices of others and the resource itself. Actors are also linked by man-made elements such as rules, institutions and collective objects.

The success of the information technologies revolution in various domains has placed strong expectations on actors' capacities to manage their own shared resources thanks to access to information systems (Young et al., 2006). However, the belief that more information leads to better and more sustainable resource management needs to be questioned, qualified and contextually defined.

Information sharing is difficult to monitor in real settings, in terms of both inputs and the way that this information is used by actors in a complex system. Thus, to explore this belief, we decided to focus on a specific case study and use an agent-based model. We chose to look at oyster farmers facing a poorly understood virus that wreaks havoc on oysters. In addition to analysing the effects of information sharing, a sub-question explored here is methodological in nature: how suitable is an agent-based model for the purposes of representing and finely controlling information sharing processes? In the model, we measure the impact of information sharing scenarios on agents and the environment, and compare the effects of information sharing to those of heterogeneity (in terms of agent decision-making), which is well known to increase exploration in agent-based models.

In the following sections, we first discuss the theoretical background and case studies that allowed us to build the model subsequently described. We then present and analyse the outcomes that we obtained from the simulation results. We conclude by explaining how our results highlight the possible effects of information sharing, and discussing the suitability of an agent-based model for exploring these effects.

\section{Material and methods}

In this section, we first present the theoretical background on information sharing. We then describe the empirical case study. Finally, we explain why we chose to use an agent-based model to explore the main question addressed by this paper.

\subsection{Information sharing for the management of collective natural resources}

The popularity of global information sharing systems, combined with the advantage of external representations over internal ones - allow us to think the previously unthinkable (Kirsh, 2010) and move towards a shared view on issues (Adams et al., 2003) - seems to confirm the usefulness of such systems.

However, such an assertion needs to be qualified. As a first caveat, in natural resource management, there is no panacea (Ostrom et al., 2007), and in general, the availability of an information system does not necessarily lead to its stated goal being met, even if the system conforms perfectly to its specifications (Mustonen-Ollila and Lyytinen, 2003; Tarhini et al., 2015). Ever since the emergence of information technologies, companies have been developing knowledge management systems at significant cost and with mixed success (Liebovitz, 2016; Malhotra, 2004). But more information sharing does not necessarily lead to the sustainable or fair use of a resource. Li (2014) provides an example of information improving the sustainable management of a groundwater resource, while Bell (2015) presents an example of the monitoring of a water resource in Pakistan leading to a decrease in water use but no improvement in equitable water distribution.

In the context of social-ecological systems, actors who use a natural resource - potentially in various different ways - are both collaborating and competing at the same time. This creates issues for information sharing systems specifically within this context, while knowledge management systems in organisations are designed with collaboration towards a shared goal in mind. Firstly, there is limited anonymity: actors may know each other and therefore be able to identify the source of a given piece of information. The availability of personspecific information may exacerbate the effects of the tragedy of the commons (Villena and Zecchetto, 2010) or negatively impact conditional cooperation (Janssen 2013). Secondly, the disclosure of private information could encourage strategic behaviour, for instance by providing incorrect information so competitors do not benefit. Thirdly, the issue of free-riding may emerge, with some actors benefiting from the work of others without having expended the same time and energy to collect and share information (Evans and Weninger, 2013). 
Information may be shared for various purposes, such as to justify a certain action (Berkes and Jolly, 2001), deal with conflicts (Adams et al., 2003), avoid depletion and pollution (Nagendra and Ostrom, 2014), or understand a resource system's dynamics (Evans and Weninger, 2013). It can also be transmitted in different ways, for example, via interpersonal exchanges on social networks (Bodin and Crona, 2009), institutional communications or schools.

In this paper, we seek to understand the potential effects of implementing information sharing systems on social-ecological systems. The observations made above should alert us to the wide variety of possible methods and purposes of sharing information, as well as the information's potential content. General studies of the effects of information have produced contrasting results depending on information type, context and intention (Apesteguia, 2006; Haynie, Hicks, and Schnier, 2009; Henry and Dietz, 2011). For this reason, we have focused here on a specific type of social-ecological system: oyster farming.

\subsection{Oyster farming case study}

We studied two examples of oyster farming, the first in the Thau Lagoon, France, and the second in nine estuaries in New South Wales (NSW), Australia. In these estuaries, oyster growers cultivate oysters of several types, including the Pacific oyster Crassostrea gigas (PO). POs account for $99 \%$ of the oysters produced in France (Oden et al., 2011) and 72\% of those produced in Australia (ABARE, 2014).

POs in the Thau Lagoon and NSW face a deadly virus, the ostreid herpes virus OsHV-1, which can, in the space of a day, kill up to $100 \%$ of a farmer's oysters - when water temperatures are above $16^{\circ}$ (Cameron and Crane, 2011). This virus has been active since 2008 in the Thau Lagoon (Oden et al., 2011), and since 2012 in the Lower Hawkesbury Estuary and other estuaries in NSW where this oyster is grown (Paul-pont et al., 2014). This type of threat has always been part of the history of oyster farming. French farmers used to grow the Portuguese oyster (Crassostrea angulata) in significant quantities prior to it being wiped out by a virus in the 1970s and subsequently replaced by the PO (Deltreil, 1973). NSW farmers growing the local Sydney rock oyster (Saccostrea glomerata) had to deal with the Qx disease that appeared in 2007 (Butt and Raftos, 2007).

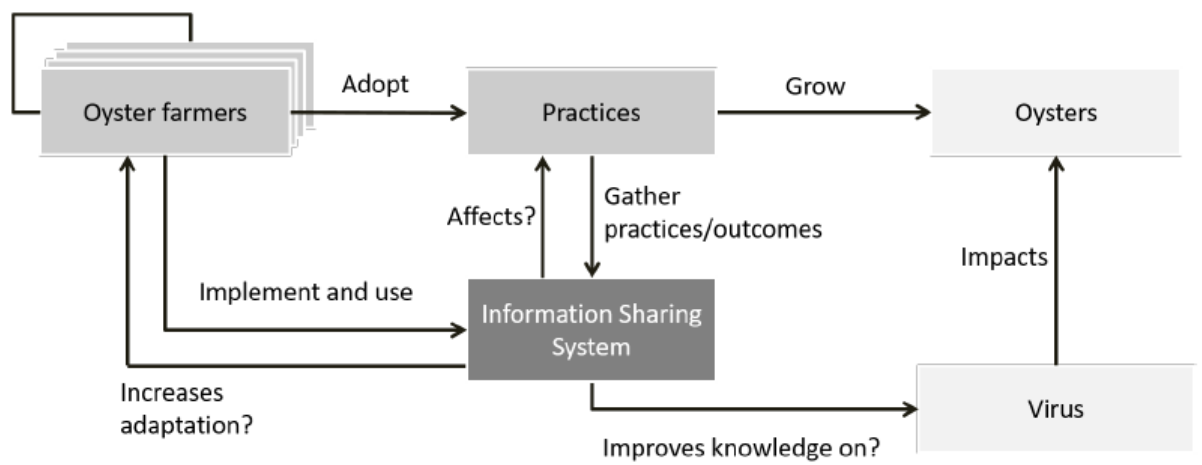

Figure 1: Description of the social-ecological system involved in oyster farming. The arrows with descriptions ending in question marks are the parts of the system investigated in the model.

Production levels have undergone a steady decline in NSW since 1976, dropping from 9,375 tons of oysters in 1976 to 3,200 tons in 2012 (OISAS, 2014), while still generating AUD 33 million in 2012. In the Thau Basin, oyster farmers produced 8,200 tons of $P O$ in 2011 , generating $€ 26.1$ million directly and $€ 86.7$ million indirectly (Gervasoni and Ritter, 2014). In the Thau Basin, in 2013, OsHV-1 killed 54\% of oysters on average, with $88 \%$ of producers reporting between $25 \%$ and $75 \%$ mortality rates (Gervasoni and Ritter, 2014).

Oyster farmers interviewed in both locations reported that the virus was their main concern and had a deep impact on their practices and future in the industry (Paget, 2016). Both scientists and oyster farmers have been conducting various studies to try to understand and tackle the virus by adapting practices (Girard et al. 2010; Paul-Pont, Dhand, and Whittington 2013; Pernet et al. 2012; Pernet et al. 2014; Whittington et al. 2015). However, these studies have not yet reached any conclusion as to what would be the best response to this situation. 
In NSW, researchers working alongside oyster farmers have developed an information sharing system called the Oyster Information Portal that gathers information about farmers' practices, such as the types and quantities of oysters grown, production figures and transfers between estuaries (Nash and Rubio-Zuazo, 2012). This is allowing oyster farmers struggling with this virus to share information about their personal practices, experiences and outcomes for the improvement of everyone's understanding. Could a system enabling information sharing be useful for oyster farmers, and what effect would this have on their understanding of the virus and response to it?

\subsection{Modelling choices}

In this paper, we intend to explore how implementing an information sharing system may impact actors' beliefs and practices, as well as overall production in a basin where oysters are cultivated and may fall victim to a virus. In doing so, we have to confront a number of difficulties linked to various aspects of the question, in addition to the general observations presented in Section 2.1 .

First of all, the act of sharing information, the main focus of this paper, is difficult to observe systematically. Linking any change in practices to a specific piece of information is virtually impossible, since actors operate within complex systems, receiving pieces of information from various sources, and learning from experience, they may adopt a certain practice for any number of reasons. Secondly, oyster farmers may or may not be willing to participate in giving their input to an information system. Thirdly, the virus is active only once per year and has considerable economic consequences, which makes experiments in the field delicate, if possible at all. Fourthly, the virus' modus operandi is still unclear, making it impossible to compare farmers' beliefs with actual virus dynamics.

By providing a virtual laboratory in silico, an agent-based model is an appealing method of overcoming these caveats, since it can be used to simulate scenarios and control parameters. Agent-based models are a suitable method to study questions of environment management (Janssen and Ostrom 2006; Le Page et al. 2013). They have been used in a wide array of domains in natural resource management, covering questions around land use (Matthews et al., 2007; Ralha et al., 2013), tourism (Anwar et al., 2007; Balbi et al., 2013), epidemiology (Almeida et al., 2010; Crooks and Hailegiorgis, 2014), common-pool resources (Schlüter and Pahl-Wostl, 2007) and water management (Feuillette et al., 2003). More precisely, in this paper, the use of such a model makes it possible to test and control various virus and information sharing scenarios. By carefully changing parameters, simulations of models can be followed thoroughly. Diverse actors interpret and use information in various ways. One of the strengths of agent-based modelling is that it allows multiple aspects to be easily modelled by implementing various decision procedures.

\section{VirusNoysters model}

The model is described using the Overview, Design and Details (ODD) protocol (Grimm et al., 2006, 2010, 2013), and more specifically the ODD+D (the additional D standing for Decision) protocol (Müller et al., 2013), an extension that includes human decision-making. This is the standard protocol for providing a thorough description of agent-based models.

\subsection{Overview}

\section{Purpose}

The purpose of the model is to investigate the effects information sharing can have on the adaptive management of a renewable natural resource used by some actors, such as oyster farmers adapting in response to the herpes virus. This model is designed to act as an exploratory model for studying the possible impacts of information, shared in a range of different ways, on the management of a natural resource.

\section{Entities, state variables and scales}

There are four main types of entities in the model: OysterFarmer, Oyster, WaterCell and Informationsystem. Figure 2 shows the model's main classes using an UML class diagram. 


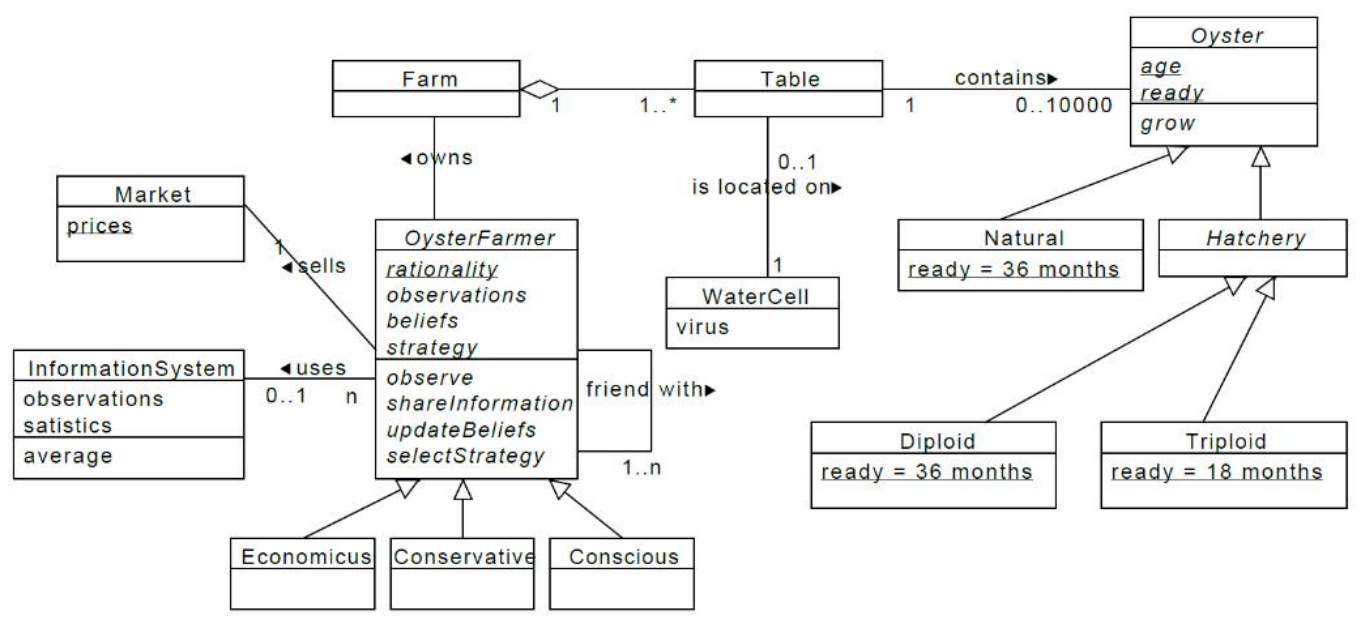

Figure 2: UML class diagram representing the main ABM classes.

Oys terFarmer These are cognitive agents. Based on interviews and the suggestion of one oyster farmer, we can identify three main types of decision-making strategies adopted by farmers: economicus, conservative and conscious. Their strategies are described under "Individual prediction" in Section 3.2. In short, they update their beliefs on the basis of various information sharing mechanisms (see below), which leads them to update their strategy and implement it. Agents belong to a social network and may have access to an information sharing system depending on the chosen scenario.

Oyster These are reactive agents. Three types of Pacific oyster (PO) can be grown. The Natural oyster is one that is caught in the wild, which can only be done in summer. The remaining two types are Hatchery oysters: Triploid and Diploid. Triploids grow in six trimesters, while diploids and natural oysters grow in 12. Both kinds of hatchery oysters can be ordered all year long. All oyster quantities are separated into batch sizes (e.g. $0-2,000$ ) of up to 10,000 oysters. These batches are located on tables.

WaterCell This is the spatial entity. Viral elements are found in the water and regularly kill oysters. Three virus scenarios are tested, including a null scenario (Figure 3 and 4 show virus scenarios and consequences for oyster farmers' expected income). The chosen virus model is the simplest of those described in (Gilligan, 2002), since the focus is on information sharing rather than epidemiology. Mortality rates are an increasing function of oyster quantity and density. The virus' impact depends on the number of oysters located on a single table, without interaction with neighboring tables. Mortality is a sigmoid function of local quantities $q: f(q)=\frac{K}{1+a \cdot \exp ^{-r q}}$ defined for $q \geq 0$ where $a$ is a parameter that allows the sigmoid mid-point abscissa to be changed, $r$ a parameter that modifies curve steepness and $K$ is the maximum of the function. Thus, a virus scenario is defined by three sets of three triplets, $S=\left\langle S_{n}, S_{d}\right.$, $\left.S_{t}\right\rangle$ where $S_{i}=$ $\left\langle a_{i}, r_{i}, K_{i}\right\rangle$ for $i \in\{n, d, t\}$, allowing the parameters of the sigmoid function to be set for each of the three types of oysters.

Informationsystem This class contains a single object designed to be a passive entity. All agents can access it. It gathers information from agents' observations (strategies and outcomes), which it then computes to provide agents with related figures.

Three simple virus behaviour scenarios are studied:

- No virus: the first scenario without mortality is the reference scenario, used as a base for comparison.

- No overlapping: in the second scenario, there is a virus affecting the oysters. The virus is the simplest to understand for agents and designed so that the mortality curves of the three different types of oysters never overlap. Whatever the quantity, natural oysters are always the best option financially.

- Overlapping: in this scenario, curves overlap at some point. This results in triploids being the oysters with the highest mortality rate once quantities have reached a specific point. As shown in Figure 4, this hypothetical scenario is more difficult for agents to explore, since the best option in terms of oyster type is dependent on quantity. 


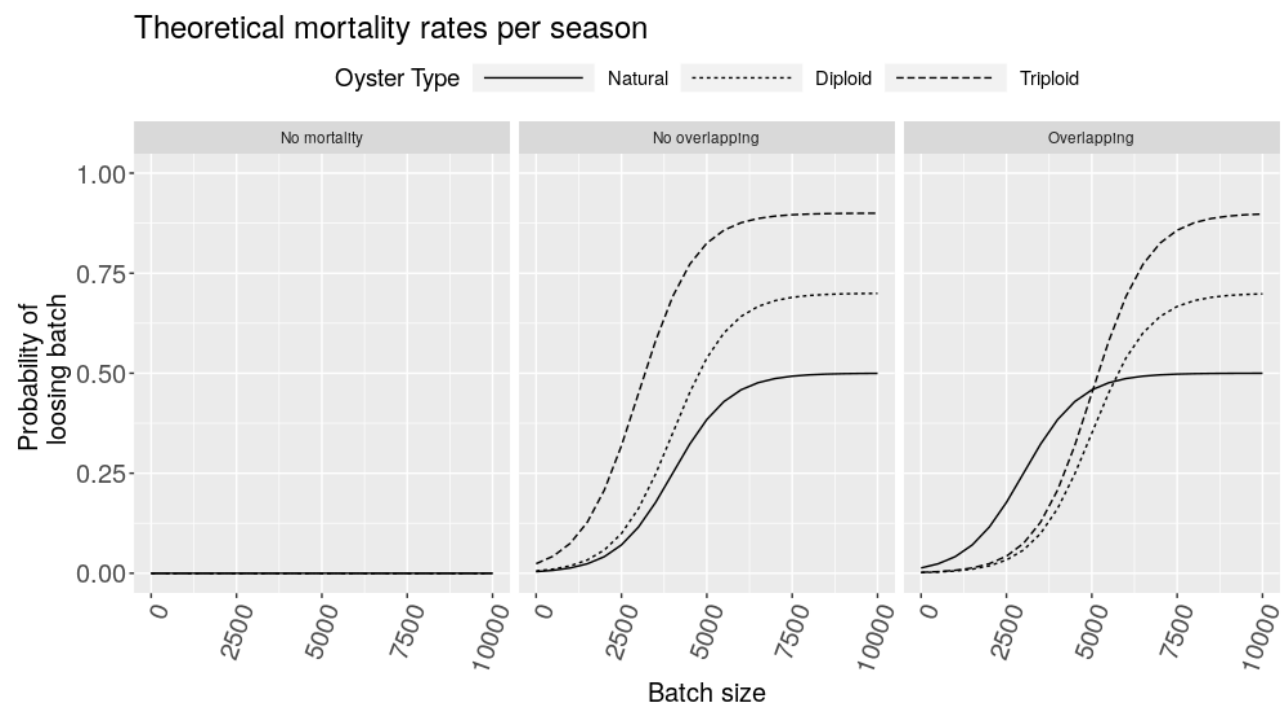

Figure 3: Annual mortality as a function of oyster quantity for the two scenarios involving virus mortality.

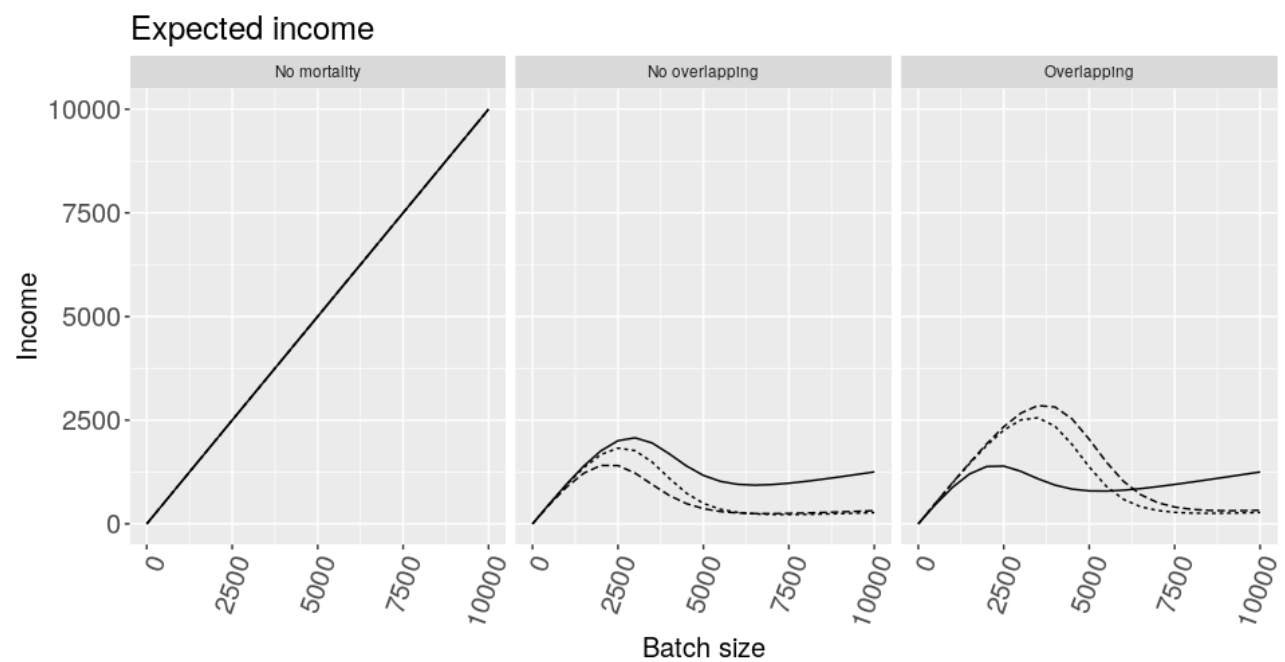

Figure 4: Theoretical expected income as a function of oyster quantity, taking into account the length of the oyster growing cycle. In the no overlapping scenario, natural oysters provide higher income regardless of quantity. Similarly, regardless of quantity, for a given oyster type, the maximum income is obtained at around 2,500-3,000 oysters per batch. In the overlapping scenario, hatchery oysters are the best option, with little difference between triploids and diploids. If oyster farmers choose batch sizes of over 6,000 oysters, the best option from a financial point of view is to choose natural oysters. The market price is exogenous and fixed.

\section{Process overview and scheduling}

Figure 5 shows the agents' relationships with the environment and the information sharing system. Depending on the scenario, an agent observes the outcomes of the practices she applies on her oyster farm, and shares this information through her network and the information sharing system. The information provided to friends and to the information system is the same, but the values that flow back to the agents are different, since they have been merged with various other pieces of information. This information is combined using a method of aggregation (see Learning) which enables the agent to update her beliefs and then choose a strategy. These strategies are implemented and impact the environment (the oysters and the virus).

The sequence of operations computed at each time step is depicted in the sequence diagram in Figure 6. Each step represents one trimester, with several steps only occurring during specific trimesters of the year. The virus attacks only during the second trimester, and oyster farmers choose their mix (types and quantities of oysters) at the end of that trimester. Natural oysters can only be caught during summer, which is the third trimester of each year. 


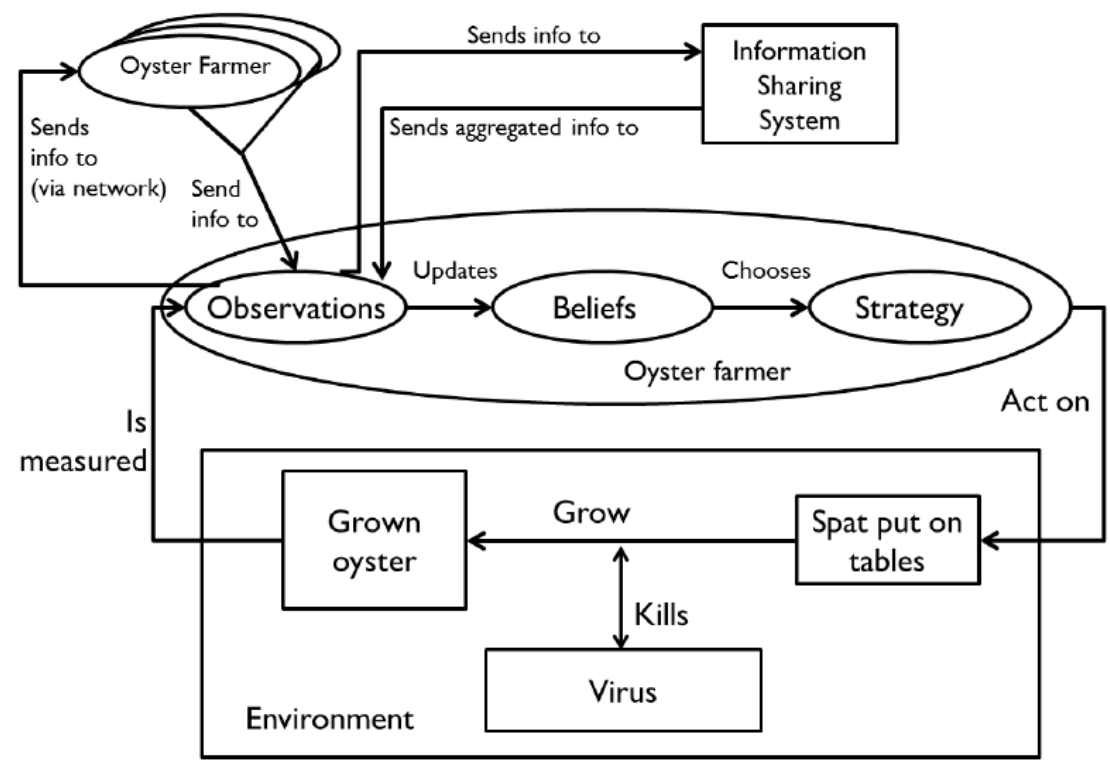

Figure 5: Main loop of the model: farmers put spat on tables and grow in the environment. The virus attacks oysters. Agents observe the outcomes and share information with others (through the network or an information sharing system). They update their beliefs that allows them to choose a strategy.

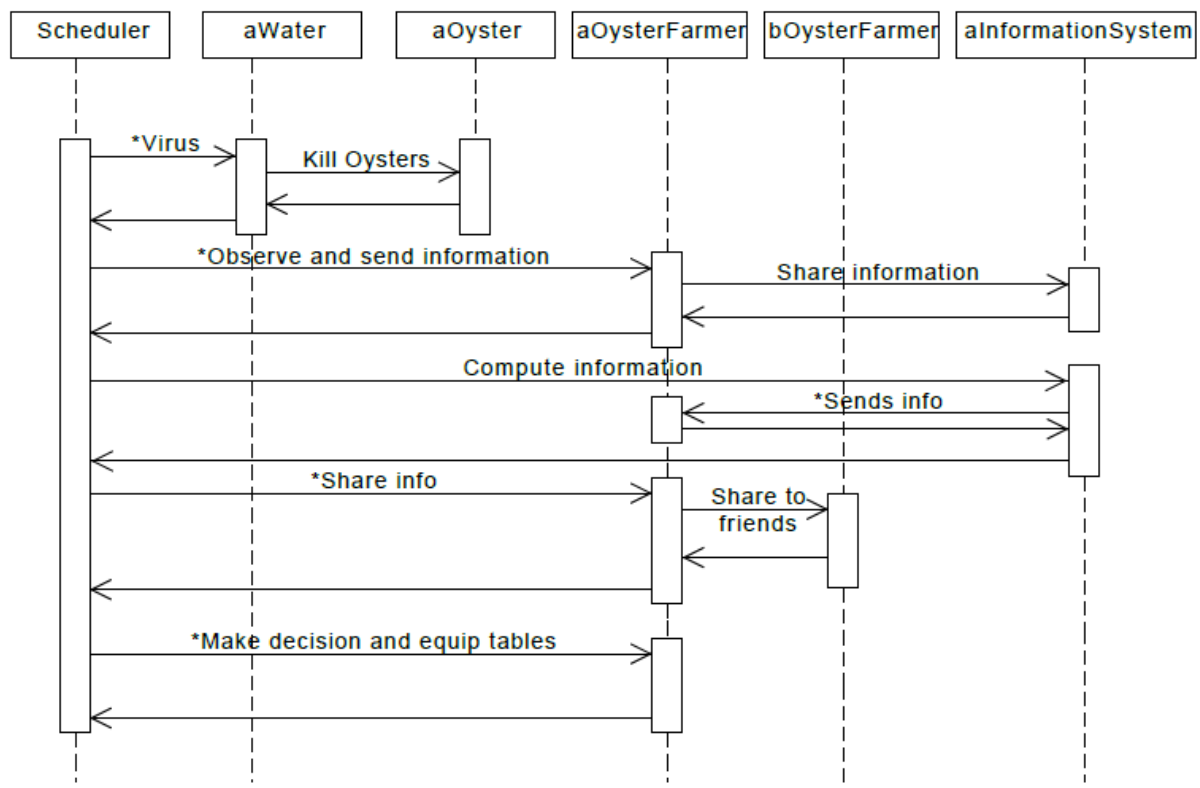

Figure 6: Sequence diagram for a time step in the model, representing one trimester.

\subsection{Design concepts}

As explained above, the model contains four main classes. Of these, Oyster, WaterCell and Informationsystem behave simply, as described in the "Entities, states variables and scale" section. We shall therefore focus now on OysterFarmer.

\section{Theoretical and empirical background}

The model combines empirical (scientific and grey literature, and a field study involving 30 interviews with farmers and meetings with actors) and theoretical elements. Theoretical choices were guided by An (2012), who suggests categories that modelers of human decision-making can use in combined human and natural systems. We made use of several of these categories. First, psychosocial and cognitive models (agents have beliefs about 
the environment and the impact of their actions on their income and production - see Individual prediction) which can be partly shaped by an institution: in this case, the information sharing system. Different decision models were used for each type of OysterFarmer (Figure 7). Specifically, a microeconomic model of utility maximization was used for economicus and a heuristic rule following procedural rationality for conservative agents (Simon, 1976).

Torra and Narukawa (Torra and Narukawa, 2007) describe in detail a large number of decision models based on information coming from different sources that have to be aggregated. Information fusion may be modelled using two frameworks: probability and fuzzy reasoning. We chose a probabilistic approach since observations (as described below) are realizations of events based on independent and identically distributed random variables. Since agents use these realizations to construct personal beliefs and need to cope with uncertainty, a probabilistic approach based on a weighted average operator seems logical (see Learning).

We adapted the main structure of the agent-based models proposed in (Ferber, 1999), in which agents interact with an environment. Agents perceive their environment and deliberate over a collection of strategies that they subsequently execute. Onto this basic structure for agent decision making we added a layer of information sharing via a network of agents and the passive entity that is the information system.

\section{Individual sensing and belief structure}

Agents measure the number of oysters produced on their farms and their mortality rates. They gather precise information on oyster type, quantity and mortality for each table. Agents also receive information on the results achieved by other oyster farmers by means of social networks and an information sharing system that feeds their beliefs (see Interaction). Beliefs consist of mortality probability values for each type of virus and batch size class (e.g. 0-1,999, 2,000-3,999, etc.).

\section{Interaction}

The virus affects each oyster table individually, and there is no specific interaction at the resource level. Interactions occur only at the information sharing level through networks and a central information sharing system. Network types influence learning and the dissemination of innovations (Bodin and Crona, 2009; Jackson, 2010). We designed three graph structures (Table 1). Information is sent to and received from friends through an agent's network. The first structure, the neighbourhood graph, emerged from interviews with oyster farmers who asserted that they mostly maintain relationships with their neighbours. This observation is possibly specific to one of the case studies (Thau Lagoon), and may not even be precise enough to describe the local network, since no social network analysis was conducted.

Table 1: Network scenarios used in the model

\begin{tabular}{lll}
\hline Type of network & Description & Expected effect \\
\hline $\begin{array}{l}\text { Neighborhood } \\
\text { graph }\end{array}$ & $\begin{array}{l}\text { Each agent is friend with immediate } \\
\text { neighbor (2 on each side) }\end{array}$ & $\begin{array}{l}\text { Slow diffusion of } \\
\text { information, local learning }\end{array}$ \\
$\begin{array}{l}\text { Preferential } \\
\text { attachment }\end{array}$ & $\begin{array}{l}\text { Variation of the small world network } \\
\text { where new nodes are attached } \\
\text { preferentially to those who are most } \\
\text { connected }\end{array}$ & $\begin{array}{l}\text { Fast diffusion of } \\
\text { information, some nodes } \\
\text { have more influence than } \\
\text { others }\end{array}$ \\
Homophily network & $\begin{array}{l}\text { Agents are preferentially linked to } \\
\text { agents who have chosen the same mix }\end{array}$ & Self-confirmation of beliefs \\
& &
\end{tabular}

The second network is typically found in many real-life examples: the preferential attachment network (Barabási and Réka, 2002). Its main characteristics are its small diameter and the presence of hubs (nodes with high degree), allowing information to be spread quickly through the network. The first two networks are static and created during initialization. 
The last type of network is based on homophily (Golub and Jackson, 2010; Jackson and López-Pintado, 2013), with oyster farmers that choose the same strategies being more likely to become friends. This network is dynamic and entirely reshaped every 12 steps (three years). Since agents generally collect information from the people with whom they have the most in common, it can be expected that this type of network would slow down innovation.

\section{Collectives}

Agents do not interact directly in a collective. However, the information sharing system is a collective object. The goal of the system is to collect information about the mortality rates experienced by oyster farmers practicing a variety of different methods. All oyster farmers are able share their personal experience (strategy and outcomes) and access aggregated information: the system averages agents' observations for all oyster types and batch size classes. It is updated annually since the virus returns once a year. The information system is based on classes of oyster quantities (e.g. 0-1,999), while mortality rates are continuous (monotonously increasing as oyster numbers increase). The more information the system gets; the closer the aggregated collective observations should be to the actual virus dynamics. In addition to the bias due to aggregating in classes, there are possible gaps in knowledge that would result from agents' choices. If no agent chooses a specific practice, there will be no observation of its outcomes (agents receive a mortality rate of 0 as information), and if too few agents choose a practice, the data may become biased due to the small number of personal experiences that they are based on, especially if these few experiences led to high mortality rates.

\section{Learning}

Agents learn by observing the environment, exchanging information with friends, and sharing through the information sharing system. For each variety of oyster, oyster farmers can be given three types of observations: their personal observations, their friends' observations and the aggregated information provided by the system. In each scenario, agents then combine (perform a weighted aggregation of) these various observations to arrive at their own beliefs on mortality rates (see Table 2 and Individual decision-making for a description of how beliefs about mortality are constructed).

Table 2: Aggregation scenarios - coefficient used for distribution aggregation. Scenarios are compared to the scenario in which no information is shared. ISS = information sharing system.

\begin{tabular}{lllll}
\hline Personal & Friends & ISS & Type & Expected outcome \\
\hline 1 & 0 & 0 & No information sharing & Slow learning curve \\
$1 / 2$ & $1 / 2$ & 0 & $\begin{array}{l}\text { Personal and friends } \\
\text { experience }\end{array}$ & Increased learning \\
$1 / 2$ & 0 & $1 / 2$ & Personal and ISS & Increased learning \\
$1 / 3$ & $1 / 3$ & $1 / 3$ & Equal trust among sources & Increased learning \\
0 & 0 & 1 & ISS only & Little exploration \\
\hline
\end{tabular}

Personal learning is the main goal of information exchange in our model, since the virus will not spread from one patch to those neighbouring it, and thus other agents' decisions are not relevant. Collective learning appears in the external representation created by the information sharing system that agents use for their own decisionmaking. This collective system, a means of gathering a collection of strategies and outcomes, creates an external memory of agents' experiences that all can access.

\section{Individual prediction}

The observations obtained during the learning phase allow agents to make their own prediction of future mortality rates and update their ideal quantity of oysters per batch, which is the first step in their decisionmaking process. Their predictions are actually beliefs and may be erroneous, since they are based on their own experience, that of their friends, and the information collected by the information sharing system. 


\section{Individual decision-making}

Figure 7 shows the activity diagram for agent decision-making. Every year, an agent has to choose sequentially their ideal quantities per batch $Q=\left\langle Q_{n}, Q_{d}, Q_{t}\right\rangle$ for each type of oyster, as well as decide on a mix $M \in \mathcal{M}$ of triploid, diploid and natural oysters, where $\mathcal{M}$ is the set of possible mixed proportions of oysters. There are seven options for $\mathcal{M}$ : only one type, or two or three types of oyster equally divided.

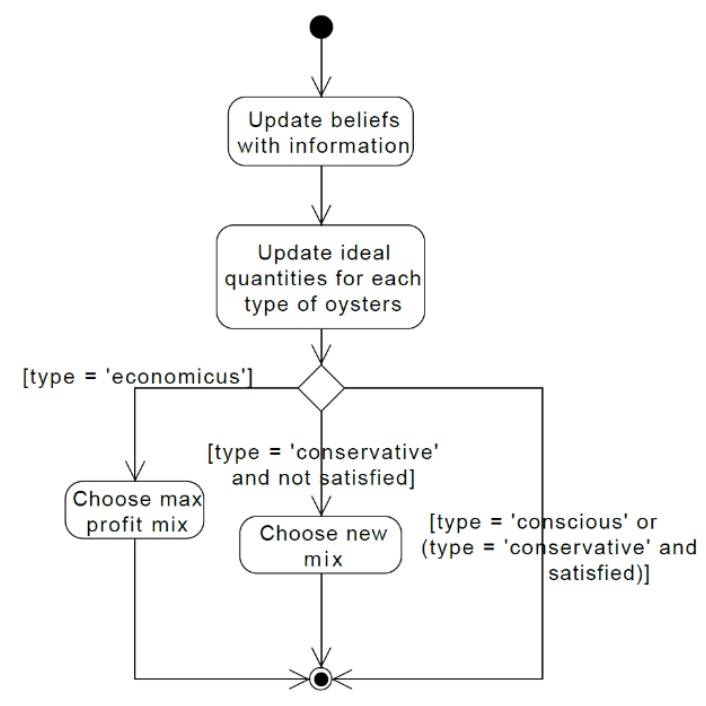

Figure 7: Activity diagram: updating of beliefs and decision-making process

As with all farmers, oyster farmers have tolerance levels, $T_{\min }$ and $T_{\max }$, where $T_{\min } \leq T_{\max }$, that they use to choose whether they will increase or decrease the fixed quantity $q>0$ that they think is good per batch. $T_{\text {min }}$, $T_{\max }$ and $q$ are parameters that can be modified to make farmers more or less averse or prone to risk. Farmers therefore use the following formula to choose their ideal quantity $Q_{i}, i \in\{t, d, n\}$, at time $t+1$, for all three types of oyster:

$$
Q_{i}(t+1)=\left\{\begin{array}{c}
Q_{i}(t)-q \text { if } \operatorname{mort}\left(Q_{i}(t)>T_{\max }\right. \\
Q_{i}(t)+q \text { if mort }\left(Q_{i}(t)<T_{\text {min }}\right. \\
Q_{i}(t) \text { otherwise }
\end{array}\right.
$$

$Q$ is updated in the same way for all agents. It is the answer to the following question: If I had to use these oysters, how many should I use per batch? After choosing these ideal quantities, agents can choose a mix by calculating their expected profit.

There are three types of oyster farmer: economicus, conservative and conscious. They differ in their decision-making process:

1. Economicus uses a microeconomic model whereby she uses the following formula to decide on the mix of oyster types that will maximize her utility (expected profit):

$$
M=\operatorname{argmax}_{M_{i} \in M} \sum_{i \in\{n, d, t\}} M_{i} \cdot Q_{i} \cdot\left(s \times\left(1-\operatorname{mort}\left(Q_{i}\right)\right)^{\operatorname{expo(i)}}-b_{i}\right)
$$

where $s$ and $b$ are, respectively, the selling (not dependent on oyster type) and buying prices, and expo( $i$ ) is the exposure of each type of oyster to the virus. Since triploids live only 18 months, they are exposed to the virus on average 1.5 times over the course of their lifetimes, whereas other types are exposed three times. $\left(1-\operatorname{mort}\left(Q_{i}\right)\right)^{\text {expo(i) }}$ corresponds to the agent's belief about the survival rate. Mortality is not dependent on oyster age.

2. Conservative's goal is to remain in the oyster farming industry. Agents will keep $M$ as long as it is satisfactory. The agent is satisfied if $M$ generates positive income. If she is no longer satisfied, then she chooses a mix $M \in M$ at random and calculates the profit using Equation 2 until she finds one that she predicts will generate positive income for her, allowing her to remain in the oyster farming industry.

3. Conscious farmers are deeply convinced that they should only cultivate natural oysters. They never change $M$, but rather, only the quantities. 


\section{Heterogeneity}

Agents are heterogeneous in the way they make decisions. As explained above and in Figure 7, this influences the mix that they choose.

\section{Stochasticity}

The virus randomly affects oysters based on fixed probabilities for each of the scenarios described in "Entities, state variables and scales" (Figure 3). During initialization, oyster farmers are given a random number of tables. The preferential attachment network has stochastic elements (the order in which agents enter the network and the agent that they first connect with) and the homophily network is shuffled every 12 steps following a stochastic rule. When they need to change their mixes, conservatives randomly try different mixes until finding an acceptable one. To smooth stochasticity, scenarios are repeated 40 times each.

\section{Observation}

Data are collected at each time step. The following indicators are recorded: mortality rates, total production, beliefs, and practices.

\subsection{Details}

\section{Implementation details}

The model runs on Cormas v.2014.5.14. (Bousquet et al., 1998; Le Page et al., 2012) a multi-agent development platform specifically designed for contexts in which humans interact with a natural environment. It provides an agent-based meta-model organized around three main classes of entities: agents, spatial entities and objects (passive entities). It is coded in the smallTalk language and uses a VisualWorks environment. We generated scenarios using R v.3.2.1 (R Core 2015) in RStudio v.0.98.1102 (RStudio 2012) and made extensive use of the tidyr (Wickham, 2014), dplyr (Wickham and François, 2015) and ggplot2 (Wickham, 2009) packages for the analysis of outcomes. This model led to the development of the first version of a module that links $\mathrm{R}$ and Cormas.

\section{Initialization}

At initialization, oyster farmers are given a random number of tables (between 1 and 10), and a random mix (natural only if the farmer is conscious). Tables are loaded with batches of oysters in the proportions of the allocated mix. Farmers are not aware of the existence of the virus and have beliefs of zero mortality for all oysters (see following section for initial parameters).

\subsection{Submodels and parameters}

We defined various scenarios on the main elements of the model. We created variations on types and quantity of oyster famers, decision-making thresholds, virus behaviour, information sharing schemes and social network structures, detailed as follows:

Oyster farmers' types (3 scenarios): A type is described with a triplet of proportions of each type of farmers

$\left\langle P_{\text {eco }}, P_{\text {conser }}, P_{\text {consc }}\right\rangle$. There are always economicus agents. The situations studied were those with economicus only $\langle 1,0,0\rangle$, economicus and conscious agents $\left\langle\frac{1}{2}, \frac{1}{2}, 0\right\rangle$ and all three types $\left\langle\frac{5}{12}, \frac{5}{12}, \frac{1}{6}\right\rangle$ (with "conscious" as a rare type).

Number of oyster farmers (4 scenarios): 10, 25, 50 and 100. All oyster farmers are given an initial budget allowing them to fill all their tables with triploids twice.

Decision-making (4 scenarios) This factor is driven by two dimensions: the size of the change in quantity, $q$, and risk aversion, $T_{\min }$ and $T_{\max }$ (see Individual decision-making and Equation 1 ). $q$ can take two values: 500 (small change) and 2,000 (big change). There are two sets of values for the $\left\langle T_{\min }, T_{\text {max }}\right\rangle$ ordered pair: $\langle 40,70\rangle$ (risk averse) and $\langle 60,80\rangle$ (risk prone).

Virus (3 scenarios) No virus and virus with or without overlapping mortality rates (Figure 3 and 4).

Information sharing and social networks (9 scenarios) This involves agents combining their personal experience, that of their friends, and information obtained from a collective system (Table 2 - see Learning). There are four options for networks: none, neighbourhood, preferential attachment and 
homophily (Table 1 - see Interactions). These networks can be combined or not with an information sharing system. We added a scenario in which agents use only the system.

In total, there are $4 \times 2+1=9$ combined scenarios for graphs and information sharing. This brings the total number of scenarios to $3 \times 4 \times 4 \times 3 \times 9=1296$. All these scenarios were run and repeated 40 times. Scenarios are summed up in Table 3.

Table 3: Experimental plan of the simulation runs Factors are the main elements of the model that take the parameters instantiated with the listed modalities.

\begin{tabular}{lllc}
\hline Factor & Parameter(s) & Modalities & $\begin{array}{c}\text { Number } \\
\text { of } \\
\text { scenarios }\end{array}$ \\
\hline Farmer type & $\left\langle P_{\text {eco }}, P_{\text {conser }}, P_{\text {consc }}\right\rangle$ & $\langle 1,0,0\rangle,\left\langle\frac{1}{2}, \frac{1}{2}, 0\right\rangle,\left\langle\frac{5}{12}, \frac{5}{12}, \frac{1}{6}\right\rangle$ & 3 \\
Number oyster farmers & Number & $10,25,50,100$ & 4 \\
Decision making & $\left\{Q t y,\left\langle T_{\text {min }}, T_{\text {max }}\right\rangle\right\}$ & $\{500,\langle 40,70\rangle\},\{500,\langle 60,80\rangle\}$, & 4 \\
& & $\{2000,\langle 40,70\rangle\},\{2000,\langle 60,80\rangle\}$ & \\
Virus & Mortality rates & Figure 3 & 3 \\
Information sharing & $\langle$ Own, Network, ISS $\rangle$ & $\langle$ Yes, Any, No $\rangle$, & 9 \\
scenarios and social & & $\langle$ Yes, Any,Yes $\rangle$, & \\
networks & & $\langle$ No, None, Yes $\rangle$ & \\
\hline
\end{tabular}

\section{Results}

In this section, we will first explain briefly the choice of indicators used to study the model's results: agents' beliefs regarding mortality rates, agents' practices, and oyster production. We first aggregated outcomes while keeping information sharing and virus scenarios separate. We then disaggregated all scenarios using a measure that captures the limitations of learning in the model, enabling a comparison of the effects of information sharing and heterogeneity in decision making.

\subsection{Overall results}

\subsubsection{Verification and indicators}

Before going further, we ensured that the computerized model was not distorting the conceptual model (David, 2013). For instance, we ran scenarios in which the virus was not active to check that actors tended to maximize the number of oysters in the basin, which should be the consequence of their decision models. Having verified this, we were confident enough to run the simulation and give the following outcomes.

In the model, actors decide upon a strategy that will allow them to adapt to a characteristic of their environment that they understand poorly. Given the context (oyster farmers dealing with a virus), and the focus of the model on studying the impact of information sharing, the three indicators that capture the key elements of the model are beliefs, practices and production. Also, we specifically detail information sharing scenarios to enable comparison.

Mortality rates may seem to be a relevant indicator. However, these rates increase as the number of oysters per batch increases (Figure 3). If agents wanted to reduce mortality rates to their absolute minimum, they would need to stop cultivating oysters. Since they aim to maximize oyster production while taking mortality into account, the lowest mortality rate is not the best solution and should not be expected as an outcome. Figure 4 shows changes in income as a function of the number of oysters cultivated, which provides a solution to the problem faced by agents. Production was therefore chosen as an environmental indicator.

\subsubsection{Analysis of belief dynamics}

We measured beliefs by investigating the dispersion of agents' beliefs about mortality rates to observe whether a collective belief would emerge. Shared information is used by agents to update their beliefs about mortality 
rates as a function of quantity for each type of oyster. Figure 8 shows changes in the dispersion of these beliefs over time, at 2, 5 and 20 years, for the non-overlapping scenario. Each graph represents the aggregation of 48 scenarios (Farmer type $x$ Number of farmers $x$ Decision making - see Table 3). Figure 9 provides a zoomed-in view on a specific situation so as to clarify Figure 8. Regardless of the information sharing scenario, a general tendency can be observed that fits the theoretical mortality rates: these increase as oyster numbers increase, but in a non-significant way.

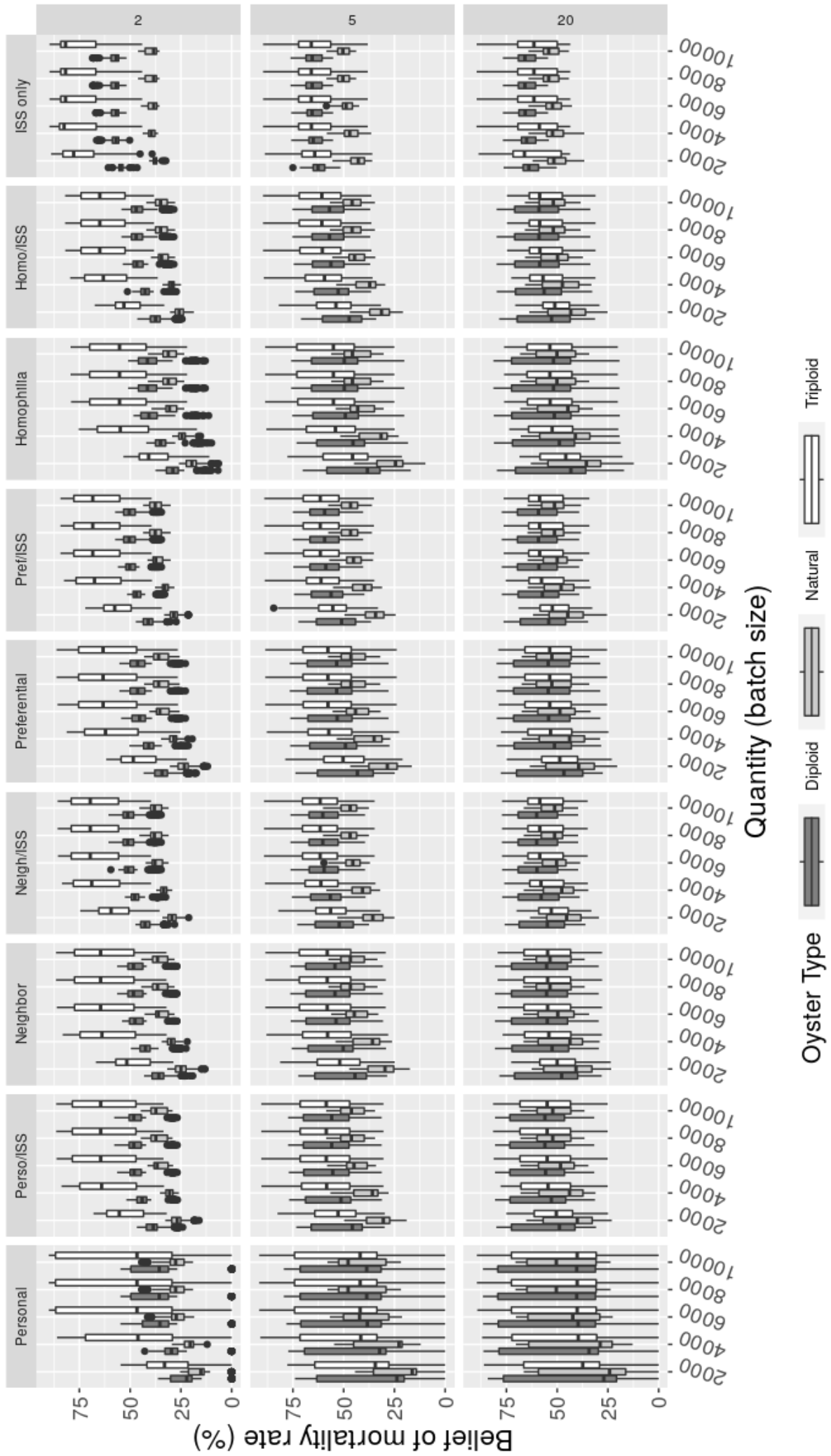

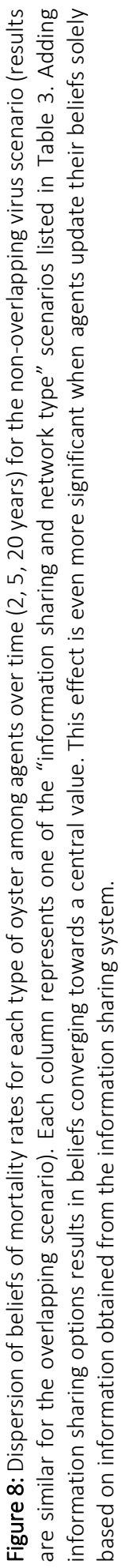




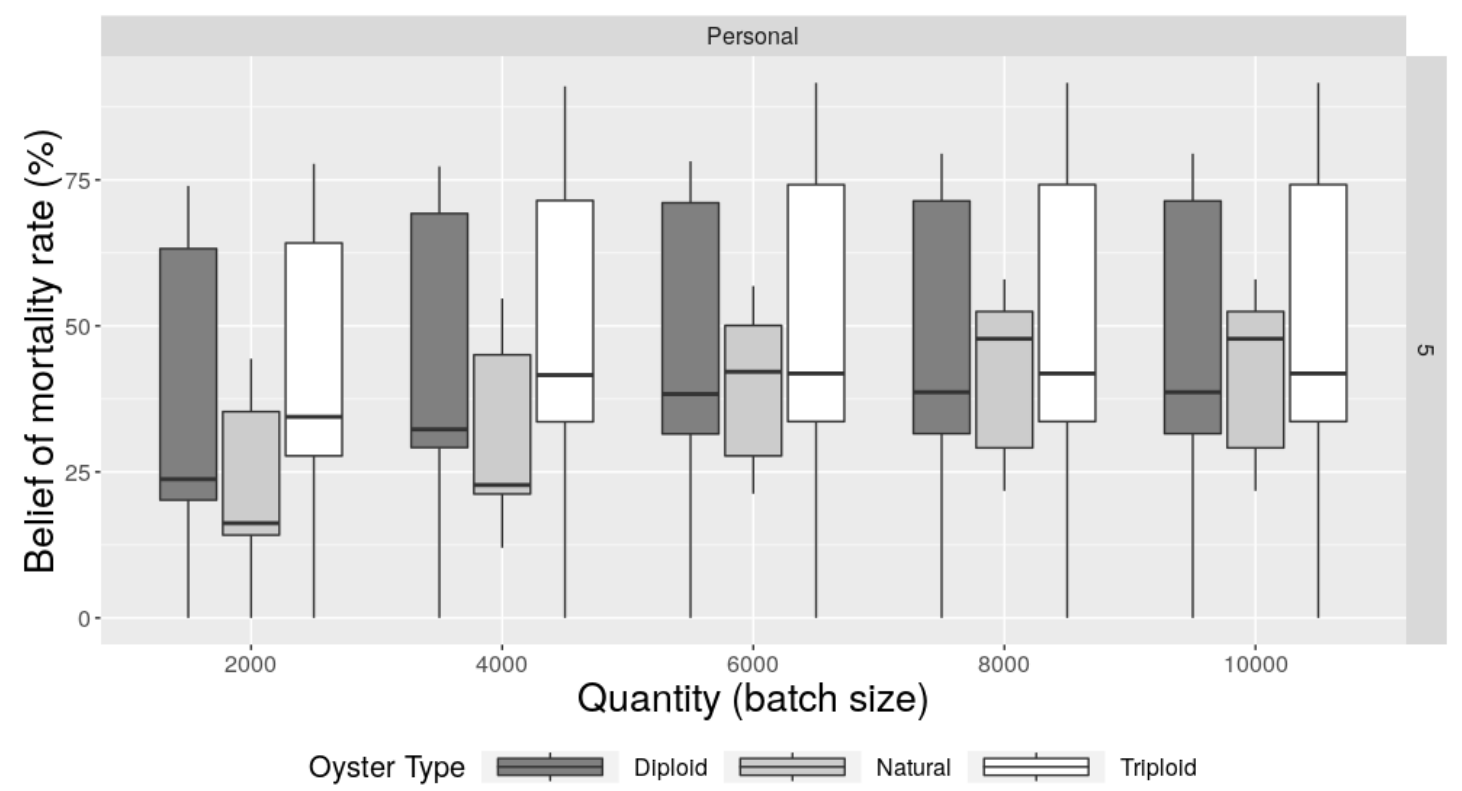

Figure 9: Zoomed-in view of the Personal $\times 5$ years scenario from Figure 8 . This graph represents the dispersion of beliefs about mortality rates among oyster farmers for the different oyster types.

Important differences can be noted between information sharing scenarios. In the personal scenario, beliefs tend to spread over time and vary considerably across scenarios, with this spreading and variation even increasing over time. The addition of social networks narrows belief dispersion in all cases, and the introduction of a central information sharing system serves to enhance this effect further. In the ISS only scenario, beliefs are the most compact. Figure 8 shows that the introduction of information sharing encourages a shared view of a phenomenon, leading to shared beliefs.

\subsubsection{Practices}

Oyster farmer agents use their beliefs to update their strategy in accordance with their decision-making process (Figure 7). Changes in practices can be understood as the combined effect of experience and information sharing.

Figure 10 shows the proportion of agents who decide to change their practice due to updating their belief. The different lines represent various agent type scenarios. It is not surprising to observe that when we add conservative agents (who change their mix only when they are not happy) and conscious agents (who grow only natural oysters) to economicus ones, the number of strategy changes is more limited. This is the result of their decision-making process. We can see that when the virus is not active, agent practices quickly converge as they decide on a definitive practice. The same result is observed in the ISS only scenario. For all other scenarios, we can observe a steep decline of all the curves and a final convergence towards the end. The slowest convergence occurs for the Personal scenario, and the addition of an information sharing system shifts the curve to the left and increases the speed of convergence.

\subsection{Production: comparing information sharing and heterogeneity of agents}

The convergence of the curves in Figure 10 led us to define a global indicator of convergence, which can be understood as the limit at which agents who have adopted a definitive strategy stop using new information. This indicator, called the change convergence, is defined as the time step after which less than $5 \%$ of agents modify their strategy. This allowed us to extract a single value for each scenario instead of the whole time series used and displayed in most of the previous graphs.

Using this compact indicator, we produced Figure 11. This graph shows production results (with production equivalent to income, since markets absorb all produce and the oyster price is fixed for all types and not dependent on production levels) as a function of this change convergence for the different agent type scenarios. Each dot is the average of the 40 repetitions of the same scenario. 


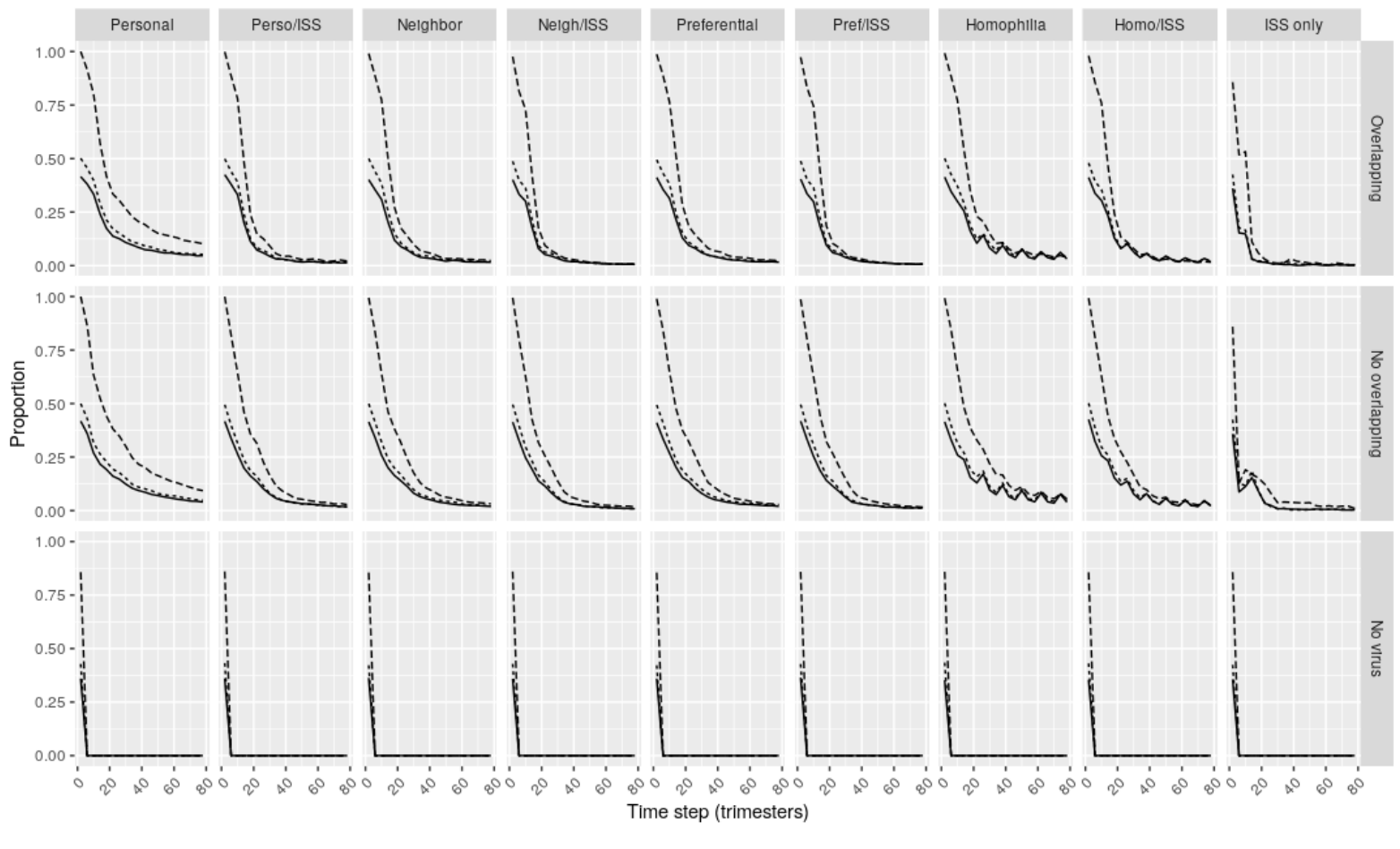

Population - Econ + Conservative + Consclous.... Econ + Conservattve --. Economicus

Figure 10: Proportion of agents changing their strategy over time for the different agent type scenarios.

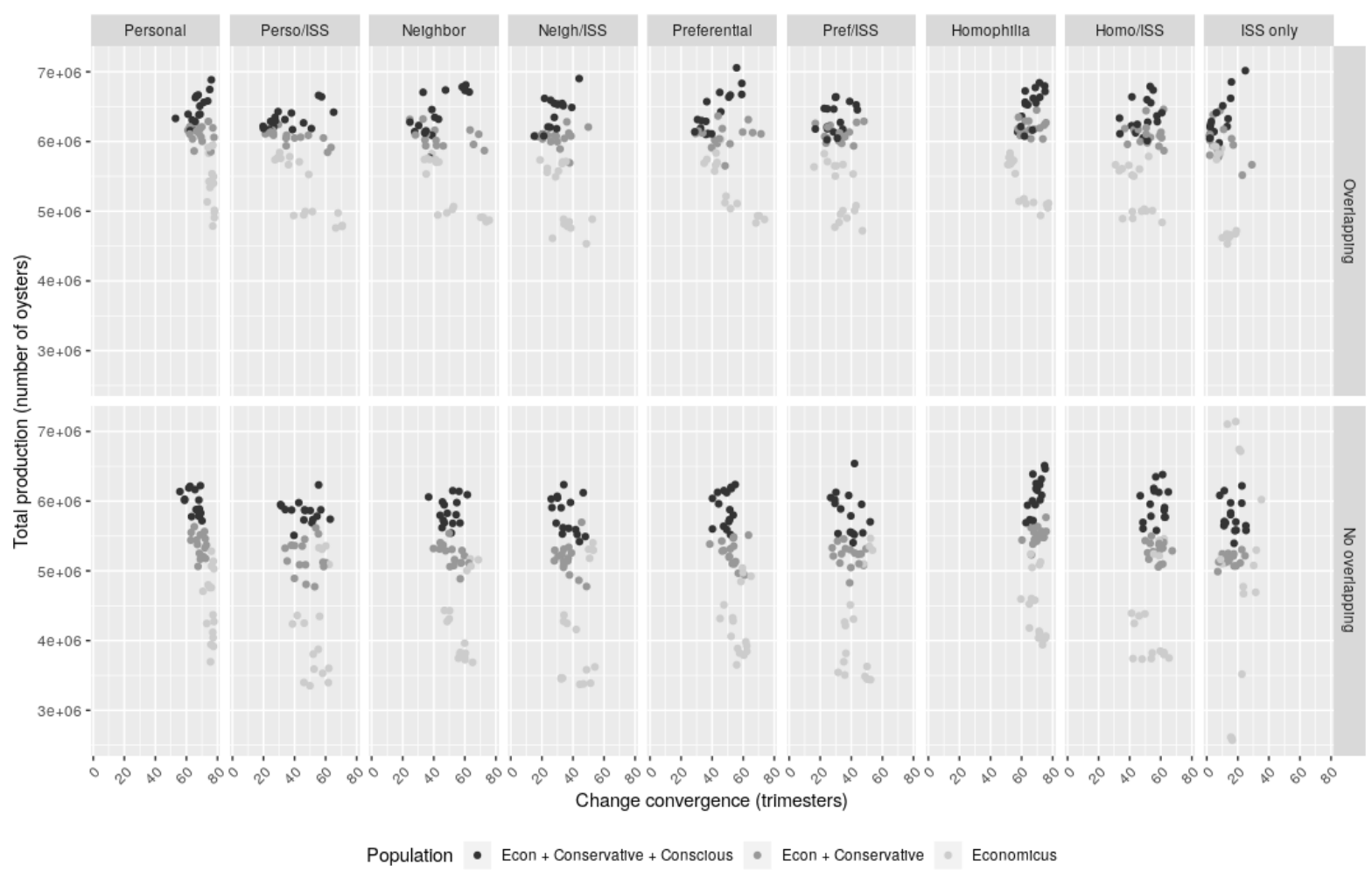

Figure 11: Total production over 20 years for the different agent type scenarios. 
Figure 11 allows us to compare the relative effect of heterogeneity and information sharing. As observed in Figure 10, the addition of an information sharing system systematically speeds up convergence, resulting in the dot clouds shifting to the left side of the plots in Figure 11. The slowest convergence is observed in the Personal and Homophily scenarios, and the fastest in the ISS only scenario. However, differences in overall production are not observed for the different information sharing scenarios, with production much more affected by the heterogeneity of agents. Light grey dots are scenarios involving only economicus agents. Adding conservative agents (dark grey dots) increases the overall production significantly, and adding conscious agents (black dots) enhances this effect further. The ISS only $\times$ No overlapping scenario provides an interesting artefact of initialization, since the dots are distributed along the production axis. This variation is due to the random initial choice of agents, leading to a fast convergence in beliefs and a choice of strategies strongly influenced by this initial strategy.

\section{Discussion}

In this paper, we explore the use of an agent-based model to investigate the impact of information sharing on a social-ecological system. The model was designed as an exploratory model. We devised precise information sharing modalities and evaluated the impact for all important aspects of the model. Given our objective, we will first examine how suitable ABMs are for studying information sharing in contexts such as that of oyster farmers. We will then discuss how the model shows convergence of agents towards a definitive practice quickly when they have access to more information sharing, but without acquiring beliefs that reflect actual virus dynamics. We will subsequently discuss how increasing the heterogeneity of agents allows them to more efficiently explore the range of practices than increased information sharing does. Finally, we will consider the limitations of the model in terms of the rigidity of the information sharing model and focus on the effect of the virus action at the patch level as opposed to a more global scale.

\subsection{Validation}

The goal of this model was to explore the impact of hypotheses about practices in various information sharing scenarios. We were not able to compare the model's results to actual changes in practices or beliefs for two reasons. Firstly, information sharing scenarios are only a kind of caricature of actual information sharing, and virus behaviour was hypothesized without strict reference to its actual behaviour (which is not known). It would be difficult to claim that we are able to replicate observed patterns of information sharing and virus dynamics under these conditions. Secondly, although some techniques allow us to assess changes in beliefs, the durability of such observed changes is questionable. As a consequence, we could not lead a proper validation. However, hypotheses that led us to the way we built the model, especially those relating to categories of actors and responses to environmental outcomes, are consistent as far as our tests and understanding of the literature are concerned. As discussed above in the Verification section, agents behave as expected in scenarios that are simple to predict, following recommendations by David (2013). For instance, in the absence of virus, all agents maximize production and conservatives never change their oyster mix.

As a matter of consistency with this approach of agent-based modelling, our results focus on possible biases linked to a specific self-evident explanation: in this case, that more information sharing would result in the best outcomes. We can observe that this is not always true. As a reminder, this model is not intended to be used as a decision aid that actors could use in real settings.

\subsection{Suitability of ABM for the study of information sharing}

Even though a central subject in the current era, to our knowledge the specific and various effects of information sharing in agent-based models was not studied per se. The use of an agent-based model proved suitable for comparing scenarios of information availability and use involving various information sharing methods. Such a model enabled us to define different uses for the same piece of information thanks to the diversity of agents' decision-making processes, ranging from agents that keep adapting to what they believe is the best economic strategy, to those who stick to their convictions. While this model focused on information sharing, other agent or network types could easily be modelled and simulated. The model was coded with this idea in mind, favouring modularity and making considerable use of object-oriented programming: information collection, information sharing and decision-making are clearly separate. 
Since information covers a wide variety of content and goals, and can be shared in a multitude of ways, with unclear or even contrasting effects cited in the literature, we chose to apply this question to a specific context: that of oyster farmers having to deal with a virus whose behaviour is poorly understood. In our model, oyster farmer agents choose a cultivation strategy and observe mortality rates. They collect information about their own practices and results, and may share them via their social network and/or an information system. Thanks to these information exchanges, oyster farmers update their beliefs and may adopt new practices.

We simulated a number of information sharing scenarios and compared several types of outcomes: for the environment (mortality rates), for agents (beliefs) and for the interaction between agents and the environment (practices). These indicators, and a comparison of these scenarios, allowed the impact of information sharing to be closely tracked for many aspects of the model.

\subsection{Effects of information sharing}

In the model, agents adapt faster and adopt a definitive practice much earlier when more ways of sharing information are offered to them, especially when they have access to a shared information system. They seem to create shared and convergent beliefs about virus dynamics much more quickly. In contrast to the case in Evans and Weninger (2013), the information sharing system in the present study does not allow agents to understand the virus behavior. They do not systematically explore, in a reliable manner, all available strategies in order to determine the real virus dynamics, but rather make do with what they have chosen and adapt their strategies accordingly. Defined in this way, access to methods of sharing information, such as social networks or information systems, leads to a convergence in beliefs and self- and community reinforcement of strategies and error, as defended in Adams et al. (2003).

\subsection{Heterogeneity vs information sharing}

Heterogeneity is known to have a decisive influence on innovation diffusion (Bohlmann et al., 2010), on environmental consequences of consumption (Raihanian Mashhadi and Behdad, 2018), or in financial markets (Schmitt and Westerhoff, 2017). Modelling heterogeneity is even a key strength of such models (An, 2012). Our results strengthen this observation: while information sharing allows for a quicker convergence of beliefs, heterogeneity has the greater impact in terms of overall production and results in more of the available strategies being explored (Figure 11). In this case, the mere existence of an external representation (the information sharing system structure is similar whatever the population) is not enough for agents to "think", and even act "the previously unthinkable" (Kirsh 2010). Economicus agents on their own are convinced that cultivating triploids is the best choice and never explore other potentially successful strategies, such as raising natural oysters, the sole goal of conscious farmers. When oyster farmers are heterogeneous, total production for the same number of agents, increases by $150 \%$, regardless of the information sharing scenario.

\subsection{Limitations}

Information structure in the model is defined a priori, as is the process of aggregating information coming from different sources. This fact limits the model's modularity. This limitation exists with the choice of sensors and in information sharing systems that are designed to collect specific types of information and analyse it in a predefined manner. These preconceptions, in combination with agents' focus on maximising production, may have prevented them from exploring all options available to them.

The virus acts at the patch level, while the virus certainly acts at a more global scale. In this context, agents face an issue common to all, but no issue in relation to their common resource: the practices of agents do not impact the collective resource, only the collective information. In social-ecological systems, actors are also linked through the resource(s) they interact with. Another model focusing on information sharing that includes a common resource could focus on a situation in which actors share information about a resource they share, such as a common-pool resource. For instance, the virus could act as a function of the total quantity of oysters in the basin, instead of acting independently on each table. Such a framing of the situation raises questions such as free-riding and strategic decision-making. However, the goal of this model was to focus on individual learning through a collective object, which led us to the choice that was adopted. 


\subsection{Next steps}

Ultimately, in the model, access to an information sharing system is not enough to allow agents to properly adapt to the virus. Such an information system should be considered part of a wider strategy of exploring how to cope with environmental dynamics that are poorly understood. We can think of heterogeneity in the model as a way of widening the exploration of options by adding other types of behaviour, which has an effect on all agents, in the same way that innovative agents or even research could offer new directions for exploration.

Information and information sharing are core concepts nowadays and their effects need to be explored while taking context into account. Creating such information systems may seem to be an appealing method of increasing scrutiny in relation to environmental dynamics and practices, since they widen the spectrum of experiences and strategies available to agents. However, this situation leads to shedding light on a limited number of elements. While information systems seem to result in a possible reframing of strategies, they also appear to prevent profound strategy changes by constraining such reframing by restraining the set of observations. Focus on such specific elements is an issue for actors in social-ecological systems due to deep uncertainty and unexpected external changes in trajectories. Thus, they may hamper actors' capacity to adapt. Creating information sharing systems may lead to counter-intuitive effects that can be analysed through agentbased modelling. The results described in this paper shed light on potential issues that may have not been considered earlier. This allows actors to be more informed and prepared.

\section{Conclusion}

Through a focus on a specific case study of oyster farmers dealing with a virus, we demonstrated the potential of agent-based modelling in tracking information sharing schemes and their effects on agents and their environment. Information sharing in this model is limited to a single information structure and a limited set of strategies. One may easily extend such framing. The study of information sharing could benefit from detailed and contextualized studies and models to explore plausible improvements and discuss possible limitations of what appear to be panaceas.

In our era of information-laden environment, due to the skyrocketing development of data and information (from information collection to information sharing) the study of the consequences of information sharing should be the highlight of more studies.

\section{References}

ABARE. (2014). Australian fisheries and aquaculture statistics 2013. Retrieved from http://data.daff.gov.au/data/warehouse/9aam/afstad9aamd003/2013/AustFishAquacStats_2013_v1.2.0 .pdf

Adams, W. M., Brockington, D., Dyson, J., \& Vira, B. (2003). Managing tragedies: understanding conflict over common pool resources. Science (New York, N.Y.), 302(5652), 1915-1916. https://doi.org/10.1126/science.1087771

Almeida, S. J. de, Martins Ferreira, R. P., Eiras, A. E., Obermayr, R. P., \& Geier, M. (2010). Multi-agent modeling and simulation of an Aedes aegypti mosquito population. Environmental Modelling and Software, 25(12), 1490-1507. https://doi.org/10.1016/j.envsoft.2010.04.021

An, L. (2012). Modeling human decisions in coupled human and natural systems: Review of agent-based models. Ecological Modelling, 229, 25-36. https://doi.org/10.1016/j.ecolmodel.2011.07.010

Anwar, S. M., Jeanneret, C. a., Parrott, L., \& Marceau, D. J. (2007). Conceptualization and implementation of a multi-agent model to simulate whale-watching tours in the St. Lawrence Estuary in Quebec, Canada. Environmental Modelling and Software, 22(12), 1775-1787. https://doi.org/10.1016/j.envsoft.2007.02.007

Apesteguia, J. (2006). Does information matter in the commons?. Experimental evidence. Journal of Economic Behavior and Organization, 60(1), 55-69. https://doi.org/10.1016/j.jebo.2004.08.002

Balbi, S., Giupponi, C., Perez, P., \& Alberti, M. (2013). A spatial agent-based model for assessing strategies of adaptation to climate and tourism demand changes in an alpine tourism destination. Environmental Modelling and Software, 45, 29-51. https://doi.org/10.1016/j.envsoft.2012.10.004 
Barabási, A.-L., \& Réka, A. (2002). Statistical mechanics of complex networks. Reviews of Modern Physics, 74(January), 48-94. https://doi.org/10.1103/RevModPhys.74.47

Bell, A. R., Shah, M. A. A., Anwar, A., \& Ringler, C. (2015). What role can information play in improved equity in Pakistan 's irrigation system ? Evidence from an experimental game in Punjab. Ecology and Society, 20(1). https://doi.org/http://dx.doi.org/10.5751/ES-07368-200151

Berkes, F., \& Folke, C. (1998). Linking social and ecological systems for resilience and sustainability. In Linking social and ecological systems: management practices and social mechanisms for building resilience (Vol. 1). Retrieved from http://books.google.com/books?hl=fr\&lr=\&id=XixuNvX2zLwC\&pgis=1

Berkes, F., \& Jolly, D. (2001). Adapting to Climate Change : Social-Ecological Resilience in a Canadian Western Arctic Community. Conservation Ecology, 5(2).

Bodin, Ö., \& Crona, B. I. (2009). The role of social networks in natural resource governance: What relational patterns make a difference? Global Environmental Change, 19(3), 366-374. https://doi.org/10.1016/j.gloenvcha.2009.05.002

Bohlmann, J. D., Calantone, R. J., \& Zhao, M. (2010). The effects of market network heterogeneity on innovation diffusion: An agent-based modeling approach. Journal of Product Innovation Management, 27(5), 741760. https://doi.org/10.1111/j.1540-5885.2010.00748.x

Bousquet, F., Bakam, I., Proton, H., \& Le Page, C. (1998). Cormas: Common-pool resources and multi-agent systems. Lecture Notes in Computer Science (Including Subseries Lecture Notes in Artificial Intelligence and Lecture Notes in Bioinformatics), 1416, 826-837. https://doi.org/10.1007/3-540-64574-8_469

Butt, D., \& Raftos, D. (2007). Immunosuppression in Sydney rock oysters (Saccostrea glomerata) and QX disease in the Hawkesbury River, Sydney. Marine and Freshwater Research, 58(2), 213-221. https://doi.org/10.1071/MF06080

Cameron, A., \& Crane, M. (2011). International OsHV-1 $\mu$ Var Workshop, Cairns, Queensland, Australia 9-10 July 2011. In Fisheries Research and Development Corporation Canberra 101 (FRDC report). Retrieved from http://www.eurl-mollusc.eu/content/download/52616/747032/file/OYSTER HERPES VIRUS WORKSHOP final REPORT.pdf

Crooks, A. T., \& Hailegiorgis, A. B. (2014). An agent-based modeling approach applied to the spread of cholera. Environmental Modelling and Software, 62, 164-177. https://doi.org/10.1016/j.envsoft.2014.08.027

David, N. (2013). Validating simulations. In B. Edmonds \& R. Meyer (Eds.), Simulating Social Complexity. https://doi.org/10.1007/978-3-540-93813-2

Deltreil, J. P. (1973). Evolution et conséquence de la mortalité de C.angulata dans le bassin d'Arcachon et l'estuaire de la Gironde de 1971 à 1973.

Evans, K. S., \& Weninger, Q. (2013). Information Sharing and Cooperative Search in Fisheries. Environmental and Resource Economics, 58(3), 353-372. https://doi.org/10.1007/s10640-013-9701-8

Ferber, J. (1999). Multi-agent system (1st ed.). United Kingdom: Pearsons.

Feuillette, S., Bousquet, F., \& Le Goulven, P. (2003). SINUSE: A multi-agent model to negotiate water demand management on a free access water table. Environmental Modelling and Software, 18(5), 413-427. https://doi.org/10.1016/S1364-8152(03)00006-9

Gervasoni, E., \& Ritter, L. (2014). Mortalités, prédation et fermetures de la commercialisation: Etat des lieux et impact pour la profession conchylicole. Retrieved from http://www.cepralmar.org/documents/mortalitespredation-fermetures-de-la-commercialisation-nbsp-etat-des-lieux-et-impact-pour-la-professionconchylicole/2014 - Rapport impact mortalite predation fermeture.pdf

Gilligan, C. a. (2002). An epidemiological framework for disease management. Advances in Botanical Research, 38, 1-64. https://doi.org/10.1016/s0065-2296(02)38027-3

Girard, S., Agundez, J., Gangnery, A., \& Vornière, J. (2010). Impact of Cultural Practices on the individual and Collective Economic Performances in Shellfish Farming: the Case of Oyster Farming in Baie Des Veys. IIFET $2010 \quad$ Montpellier Proceedings, $1-12 . \quad$ Retrieved from http://ir.library.oregonstate.edu/xmlui/handle/1957/38641

Golub, B., \& Jackson, M. O. (2010). How Homophily Affects the Speed of Contagion, Best Response and Learning. Learning, (February), 1-58.

Grimm, V., Berger, U., Bastiansen, F., Eliassen, S., Ginot, V., Giske, J., ... DeAngelis, D. L. (2006). A standard protocol for describing individual-based and agent-based models. Ecological Modelling, 198(1-2), 115126. https://doi.org/10.1016/j.ecolmodel.2006.04.023

Grimm, V., Berger, U., DeAngelis, D. L., Polhill, J. G., Giske, J., \& Railsback, S. F. (2010). The ODD protocol: A review and first update. Ecological Modelling, 221(23), 2760-2768. https://doi.org/10.1016/j.ecolmodel.2010.08.019

Grimm, V., Polhill, G., \& Touza, J. (2013). Documenting Social Simulation Models: The ODD Protocol as a 
Standard. In B. Edmonds \& R. Meyer (Eds.), Simulating Social Complexity (pp. 117-133). https://doi.org/10.1007/978-3-540-93813-2

Haynie, A. C., Hicks, R. L., \& Schnier, K. E. (2009). Common property, information, and cooperation: Commercial fishing in the Bering Sea. Ecological Economics, 69(2), 406-413. https://doi.org/10.1016/j.ecolecon.2009.08.027

Henry, A. D., \& Dietz, T. (2011). Information, networks, and the complexity of trust in commons governance. International Journal of the Commons, 5(2), 188-212.

Jackson, M. O. (2010). Social and economic networks (P. university Press, Ed.).

Jackson, M. O., \& López-Pintado, D. (2013). Diffusion and contagion in networks with heterogeneous agents and homophily. Network Science, 1(01), 49-67. https://doi.org/10.1017/nws.2012.7

Janssen, MA, \& Ostrom, E. (2006). Empirically based, agent-based models. Ecology and Society, 11(2). Retrieved from http://www.ecologyandsociety.org/vol11/iss2/art37/

Janssen, Marco. (2013). The Role of Information in Governing the Commons: Experimental Results. Ecology and Society, 18(4), 1-27. https://doi.org/http://dx.doi.org/10.5751/ES-05664-180404

Kirsh, D. (2010). Thinking with external representations. Al and Society, 25(4), 441-454. https://doi.org/10.1007/s00146-010-0272-8

Le Page, C., Bazile, D., Becu, N., Bommel, P., Etienne, M., Mathevet, R., \& Weber, J. (2013). Agent-based modelling and simulation applied to environmental management. In B. Edmonds \& R. Meyer (Eds.), Simulating Social Complexity (pp. 499-540). https://doi.org/10.1007/978-3-540-93813-2

Le Page, C., Becu, N., Bommel, P., \& Bousquet, F. (2012). Participatory Agent-Based Simulation for Renewable Resource Management : The Role of the Cormas Simulation Platform to Nurture a Community of Practice. Journal of Artificial Societies and Social Simulation, 15, 10. Retrieved from http://jasss.soc.surrey.ac.uk/15/1/10.html

Li, J., Michael, H. A., Duke, J. M., Messer, K. D., \& Suter, J. F. (2014). Behavioral response to contamination risk information in a spatially explicit groundwater environment: Experimental evidence. Water Resources Research, 50(8), 6390-6405. https://doi.org/10.1002/2013WR015230

Liebovitz, J. (2016). Successes and failures of knowledge management. Morgan Kaufmann.

Malhotra, Y. (2004). Why knowledge management systems fail: enablers and constraints of knowledge management in human enterprises. Handbook on Knowledge Management 1, 577-599. https://doi.org/10.1007/978-3-540-24746-3_30

Matthews, R. B., Gilbert, N. G., Roach, A., Polhill, J. G., \& Gotts, N. M. (2007). Agent-based land-use models: a review of applications. Landscape Ecology, 22(10), 1447-1459. https://doi.org/10.1007/s10980-0079135-1

McGinnis, M. D., \& Ostrom, E. (2014). Social-ecological system framework: Initial changes and continuing challenges. Ecology and Society, 19(2). https://doi.org/10.5751/ES-06387-190230

Müller, B., Bohn, F., Dreßler, G., Groeneveld, J., Klassert, C., Martin, R., ... Schwarz, N. (2013). Describing human decisions in agent-based models - ODD+D, an extension of the ODD protocol. Environmental Modelling and Software, 48, 37-48. https://doi.org/10.1016/j.envsoft.2013.06.003

Mustonen-Ollila, E., \& Lyytinen, K. (2003). Why organizations adopt information system process innovations: a longitudinal study using Diffusion of Innovation theory. Information Systems Journal, 13, 275-297.

Nagendra, H., \& Ostrom, E. (2014). Applying the social-ecological system framework to the diagnosis of urban lake commons in Bangalore , India. Ecology and Society, 19(2). https://doi.org/http://dx.doi.org/10.5751/ES-06582-190267

Nash, C., \& Rubio-Zuazo, A. M. (2012). Monitoring the canaries of our catchments. 21st NSW Coastal Conference. Retrieved from http://ro.uow.edu.au/cgi/viewcontent.cgi?article=1015\&context=smfc\&seiredir=1\&referer=http\%253A\%252F\%252Fscholar.google.fr\%252Fscholar\%253Fq\%253Dcanary\%252Bof\% 252Bthe\%252Bestuary\%252Boysters\%2526btnG\%253D\%2526hl\%253Dfr\%2526as_sdt\%253D0\%25252C5 \#search $=\% 25$

Oden, E., Martenot, C., Berthaux, M., Travaillé, E., Malas, J. P., \& Houssin, M. (2011). Quantification of ostreid herpesvirus 1 (OsHV-1) in Crassostrea gigas by real-time PCR: Determination of a viral load threshold to prevent summer mortalities. Aquaculture, 317(1-4), 27-31. https://doi.org/10.1016/j.aquaculture.2011.04.001

OISAS. (2014). NSW Oyster Industry Sustainable Aquaculture Strategy Second edition - 2014. Retrieved from http://www.dpi.nsw.gov.au/_data/assets/pdf_file/0005/506939/oisas-second-edition-2014.pdf

Ostrom, E. (2007). A diagnostic approach for going beyond panaceas. Proceedings of the National Academy of Sciences of the United States of America, 104(39), 15181-15187. https://doi.org/10.1073/pnas.0702288104 
Ostrom, E., Janssen, M. a, \& Anderies, J. M. (2007). Going beyond panaceas. Proceedings of the National Academy of Sciences of the United States of America, 104(39), 15176-15178. https://doi.org/10.1073/pnas.0701886104

Paget, N. (2016). Facing threats by sharing information for renewable natural resources management. Paris Dauphine.

Paul-Pont, I., Dhand, N. K., \& Whittington, R. J. (2013). Influence of husbandry practices on OsHV-1 associated mortality of Pacific oysters Crassostrea gigas. Aquaculture, 412-413, 202-214. https://doi.org/10.1016/j.aquaculture.2013.07.038

Paul-pont, I., Evans, O., Dhand, N. K., Rubio, A., Coad, P., \& Whittington, R. J. (2014). Descriptive epidemiology of mass mortality due to Ostreid herpesvirus-1 ( OsHV-1) in commercially farmed Paci fi c oysters ( Crassostrea gigas ) in the Hawkesbury River estuary, Australia. Aquaculture, 422-423, 146-159. https://doi.org/10.1016/j.aquaculture.2013.12.009

Pernet, F, Barret, J., Le Gall, P., Corporeau, C., Dégremont, L., Lagarde, F., ... Keck, N. (2012). Mass mortalities of Pacific oysters Crassostrea gigas reflect infectious diseases and vary with farming practices in the Mediterranean Thau lagoon, France. Aquaculture Environment Interactions, 2(3), 215-237. https://doi.org/10.3354/aei00041

Pernet, Fabrice, Lagarde, F., Jeannée, N., Daigle, G., Barret, J., Le Gall, P., ... D’orbcastel, E. R. (2014). Spatial and temporal dynamics of mass mortalities in oysters is influenced by energetic reserves and food quality. PloS One, 9(2), e88469. https://doi.org/10.1371/journal.pone.0088469

Raihanian Mashhadi, A., \& Behdad, S. (2018). Environmental impact assessment of the heterogeneity in consumers' usage behavior: An agent-based modeling approach. Journal of Industrial Ecology, 22(4), 706719. https://doi.org/10.1111/jiec.12622

Ralha, C. G., Abreu, C. G., Coelho, C. G. C., Zaghetto, A., Macchiavello, B., \& Machado, R. B. (2013). A multi-agent model system for land-use change simulation. Environmental Modelling and Software, 42, 30-46. https://doi.org/10.1016/j.envsoft.2012.12.003

Schlüter, M., \& Pahl-Wostl, C. (2007). Mechanisms of resilience in common-pool resource management systems: an agent-based model of water use in a river basin. Ecology and Society, 12(2), 4. https://doi.org/4

Schmitt, N., \& Westerhoff, F. (2017). Heterogeneity, spontaneous coordination and extreme events within largescale and small-scale agent-based financial market models. Journal of Evolutionary Economics, 27(5), 1041-1070. https://doi.org/10.1007/s00191-017-0504-x

Simon, H. A. (1976). From substantive to procedural rationality. In 25 years of economic theory (pp. 65-86). Boston, MA: Springer.

Tarhini, A., Asanka Gamagedara Arachilage, N., Masa'deh, R., \& Abbasi, M. S. (2015). A Critical Review of Theories and Models of Technology Adoption and Acceptance in Information System Research. International Journal of Technology Diffusion, 6(October-December), 58-77. https://doi.org/10.4018/IJTD.2015100104

Team, R. C. (2015). R: A Language and Environment for Statistical Computing. Vienna, Austria: R Foundation for Statistical Computing.

Team, Rs. (2012). RStudio. Boston, MA: RStudio: Integrated Development Environment for R.

Torra, V., \& Narukawa, Y. (2007). Modeling decisions: information fusion and aggregation operators. Springer Science \& Business Media.

Villena, M. G., \& Zecchetto, F. (2010). Subject-Specific Performance Information can Worsen the Tragedy of the Commons: Experimental Evidence. SSRN Electronic Journal. https://doi.org/10.2139/ssrn.1732862

Whittington, R. J., Dhand, N. K., Evans, O., \& Paul-Pont, I. (2015). Further observations on the influence of husbandry practices on OsHV-1 $\mu$ Var mortality in Pacific oysters Crassostrea gigas: Age, cultivation structures and growing height. Aquaculture, 43-97. https://doi.org/10.1016/j.aquaculture.2014.12.040

Wickham, H. (2009). ggplot2: elegant graphics for data analysis. Springer New York.

Wickham, H. (2014). tidyr: Easily Tidy Data with spread() and gather() Functions. (version 0.2.0).

Wickham, H., \& François, R. (2015). dplyr: A Grammar of Data Manipulation. (version 0.4.2.).

Young, O. R., Berkhout, F., Gallopin, G. C., Janssen, M. a., Ostrom, E., \& van der Leeuw, S. (2006). The globalization of socio-ecological systems: An agenda for scientific research. Global Environmental Change, 16(3), 304-316. https://doi.org/10.1016/j.gloenvcha.2006.03.004 